\title{
REFLECTION
}

\section{The Lost Pillar: Does Continuity of Care Still Matter?}

\section{David Loxterkamp, MD}

Northern Light Family Medicine Residency Program, Bangor, Maine
Conflicts of interest: author reports none.

\section{CORRESPONDING AUTHOR}

David Loxterkamp Northern Light Family Medi-

cine Residency Program 895 Union Street, Suite 12 Bangor, ME 04401-3010 david.loxterkamp@gmail.com

\begin{abstract}
Continuity of care has long held a hallowed place in the halls of family medicine. Indeed, it is one of the 4 pillars of an ideal family practice, along with first contact, comprehensive, and coordinated care. But what does it mean to the patient, the doctor, and our sense of identity and purpose? And why, in recent years, has it receded from the discourse of family medicine values? This author suggests that continuity is an expression of the value we place on human relationships, a contract of sorts with the people we care for both inside and outside the office. Such relationships are not lightly discarded, for they serve us best in the long haul when our own sense of identity and purpose is tested and worn.
\end{abstract}

Ann Fam Med 2021;19:553-555. https://doi.org/10.1370/afm.2736.

"I find my thoughts drifting to the Sabbath, the day of rest... when one can feel that one's work is done, and one may, in good conscience, rest." —Oliver Sacks

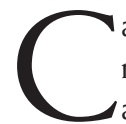
all me a dinosaur, one of a dying breed. Shortly after completing my training in family medicine, I moved to a small town in Maine and remained there-in the same practice, same house, with the same wife and kids. You could say that I had found what I was looking for

But it would be more accurate to say that I discovered it in the care of patients and by living alongside them in community. Neighbors, patients, and colleagues taught me what I needed to know. So did my consultants, who reminded me that I chose this job, so I should own its responsibilities. That patients need us in the middle of the night, too, so prepare for it. And that doctors are not the final judge of the value of their care.

These final words of advice hit home in a story I heard shortly after I arrived in town.

Horace Jackson had been a fine amateur baseball player in his youth and worked on a local dairy farm for most of his productive years. Now nearing 80 , he could barely get around on his bowed knees. He sought help from a local orthopedic surgeon; joint replacement seemed the logical next step. Before long he had undergone an uneventful operation at our small county hospital.

Complications ensued. He required a foley catheter after surgery; this eventually led to a prostatectomy for bladder outlet obstruction. During that admission, he somehow strained his leg and developed slippage of his knee cap. Despite extensive physical therapy, Horace returned to the hospital a year later for a surgical repair. Unfortunately, the knee became infected. The surgeon did his best to drain the knee and administer antibiotics, but within a month Horace was back in the hospital to have his knee prosthesis removed and an external fixation device applied.

Things went well for a couple of weeks. Then Horace developed forceful bleeding from his wound. It was determined that a pin had eroded through an artery, so the pin was removed and the artery tied off. But the bleeding continued and the knee became infected. After consultation with the patient and his family, a decision was made to proceed with the eighth and final operation: an above-knee amputation. 
Several months later-and 5 years after the original operation-Horace made a follow-up visit to his orthopedic surgeon. Vital signs were taken, the wound examined. Then, sitting in his wheelchair, which was now his staple mode of transportation, Horace clasped the hands of the surgeon and gazed upward. "Doc," he said in his soft, slow Maine cadence, "ya done a wonderful job."

Against the measure of perfection, the doctor had done a terrible job. Nor was his retelling of the story a strong endorsement for his operative skills. No, his was a lesson in humility and gratitude, gifted to him and shared for our benefit.

After more than 3 decades in a full-spectrum general practice, I joined the faculty of a nearby residency program. Part of my clinical duties included teaching on the inpatient service. Patients come to our referral hospital from all over the northern half of the state. And to each of them I pose the same question, "Who is your primary care physician?" Invariably I hear something like, "Well, old Doc Jones was my family doctor until 3 or 4 years ago. After he retired, I see someone different every time I go to clinic." The situation is no better at our teaching center, where, despite an obvious intent to do better, the rate of continuity never rises above $25 \%$. Is this what we are teaching? Do we consider this to be good medicine?

Caring for patients for the duration of their illness, and not just at the start of it, was once a hallmark of primary care. First contact, comprehensive care, continuity, and care coordination came to be known as the 4 pillars. ${ }^{1}$ Now, in every patient-centered medical home around the country, a technician is designated to evaluate the acutely ill, handle "transitions of care," and align every problem with a specialty referral. Continuity, on the other hand, is ignored because it cannot be off-loaded.

In my father's day, and indeed my own, one doctor could serve these many roles. Now we prefer to create teams, so-called, to satisfy the various needs of our patients. In spite of this, very few of them consider "the team" to be their doctor.

Yet we have created a war chest to defend the value of continuity. Nyweide showed that small increases in continuity can decrease the rate of preventable hospitalizations among older adults. ${ }^{2}$ Gupta and Bodenheimer, in their commentary, cite studies that show a positive correlation between continuity and preventive and chronic care services, patient and clinician satisfaction, lower hospital utilization rates, lower costs, and lower mortality rates among the elderly. ${ }^{3}$ Bazemore confirmed that higher rates of continuity are associated with lower medical costs and hospitalization rates. ${ }^{4}$ And a 2020 systematic review and related POEM found evidence for an inverse relationship between allcause mortality and continuity. ${ }^{5}$

A dozen years ago Guthrie and colleagues published a paper called "Continuity Still Matters." ${ }^{1 n}$ In it they identified the 3 kinds of continuity-informational, managerial, and relational—but placed relational continuity at the center of good practice. They saw it as dependent upon a clinician's willingness to take personal responsibility for the patient's longitudinal care. Stephens used the term "moral responsibility" to describe the act of allowing another person to depend on $\mathrm{you}_{i}^{7}$ Daaleman felt "bound to the care of patients" whose self-respect had been hollowed by illness ${ }^{8}{ }_{i}$ Egnew saw healers as "part of and connected to the patient's life narrative." ${ }^{\prime 9}$ Frey reminds us that when self-enrichment comes at the expense of a closer relationship to our patients, it risks compromising the very values that made it necessary to form our specialty. ${ }^{10}$

Then why have we abandoned continuity? Patients, we are told, are highly mobile and prefer the 24-hour convenience of the emergency department or urgent care facility; administrators blame recruitment shortfalls and productivity targets; physicians are less attached to their patients and to the communities they serve. But there is another reason, more insidious and harder to defend: we have been pulled into the orbit of mainstream medicine. Primary care physicians are trained and employed in the transactional world of episodic care. On inpatient services, in emergency departments, and at every urgent care center, patients are treated by doctors who see them once. Here they are given a hypothetical diagnosis (as all diagnoses are) and offered "care" in the form of a test, a drug, a referral, or all 3. The doctor rarely learns what happens next. Did the patient improve? Have the symptoms recurred? Do we know the underlying cause? In such settings there is no incentive, let alone capacity, to answer these questions. So, the machine churns on.

And in primary care, we have followed suit. We have created urgent care centers within our primary care offices. We are quick to refer the needy, demanding, or inscrutable patient because they are too timeconsuming. There is no reason to work in our acutely ill patients because "ours" is now a team and we have a schedule to keep. And our workday ends at 5:00 PM.

The result is consequential (Table 1). In our employed positions, we find it easier to remain anonymous than take personal responsibility for the patient's care. In a crunch, we work the protocol rather than invent solutions. We are more concerned about safety (the hospital's, our own) than the patient's right to self-determination. We are rewarded for meeting shortterm metrics (lower blood pressure, $A_{1 C}$, or low-density lipoprotein $[\mathrm{LDL}])$ rather than long-term strategies. 


\section{Table 1. Episodic vs Continuity Care}

\begin{tabular}{ll}
\hline Episodic Care & Continuity Care \\
\hline Does his or her job & Accepts responsibility for the patient \\
Accedes to the protocol & Finds a creative solution \\
More concerned about safety & More concerned about self-determination \\
Sets short-term goals & Sets long-term goals \\
Knows the chart & Knows the patient \\
Provides timely documentation & Provides timely communication \\
Pays attention to details & Pays attention to the whole \\
\hline
\end{tabular}

"I find my thoughts, increasingly, not on the supernatural or spiritual but on what is meant by living a good and worthwhile life-achieving a sense of peace within oneself. I find my thoughts drifting to the Sabbath, the day of rest, the seventh day of the week, and perhaps the seventh day of one's life as well, when one can feel that one's work is done, and one may, in good conscience, rest." ${ }^{\prime \prime}$

Family medicine is forever changing. The majority of us are now employed in suburban and academic practices that make continuity much more difficult to deliver. Not so a half-century ago when it was expected of us and seemed inescapable. Living in small, stable communities kept us close to the consequences of our actions, where every convenience or personal advancement was a trade-off with other cherished values. Sometimes we stumbled upon this truth. Sometimes we erected barriers that shaded it from view. But this I know: while it is possible feel honored at any stage of one's career, the real satisfactions in the practice of medicine are meted out over time and acquired through patience, self-sacrifice, and humility, and in continuity with the old-fashioned values of family medicine.

To read or post commentaries in response to this article, go to https://www.AnnFamMed.org/content/19/6/553/tab-e-letters.

Key words: continuity of care; relationship; residency training

Submitted February 9, 2021; submitted, revised, April 5, 2021; accepted April 27, 2021.

Acknowledgments: I am indebted to Robert Keller, MD, whose telling of "Doc, Ya Done a Wonderful Job" was published in the AAOS Bulletin in January, 1990. His example has inspired me throughout my career.

\section{References}

1. Starfield B. Primary Care: Concept, Evaluation, and Policy. Oxford University Press; 1992.

2. Nyweide DJ, Anthony DL, Bynum JP, et al. Continuity of care and the risk of preventable hospitalization in older adults. JAMA Intern Med. 2013;173(20):1879-1885.

3. Gupta R, Bodenheimer T. How primary care practices can improve continuity of care. JAMA Intern Med. 2013;173(20):1885-1886.

4. Bazemore A, Petterson S, Peterson LE, Bruno R, Chung Y, Phillips RL Jr. Higher primary care physician continuity is associated with lower costs and hospitalizations. Ann Fam Med. 2018;16(6):492-497.

5. Baker R, Freeman GK, Haggerty JL, Bankart MJ, Nockels KH. Primary medical care continuity and patient mortality: a systematic review. Br J Gen Pract. 2020;70(698):e600-e611.

6. Guthrie B, Saultz JW, Freeman GK, Haggerty JL. Continuity of care matters. BMJ. 2008;337:a867.

7. Stephens GG. The Physician as a Moral Agent. The Intellectual Basis of Family Practice. Winter Publishing; 1982.

8. Daaleman TP. What is my value as a doctor? Ann Fam Med. 2020; 18(6):558-560.

9. Egnew TR. The meaning of healing: transcending suffering. Ann Fam Med. 2005;3(3):255-262.

10. Frey JJ. Colluding with the decline of continuity. Ann Fam Med. 2018;16(6):488-489.

11. Sacks O. Gratitude. Alfred A. Knopf; 2015. 